text boxes, bulleted text, and illustrations). Needed materials should be included.

Results: In the booklet, factors that may influence fatigue are demonstrated by a hanging mobile toy, a device with stars or other figures hanging from the ceiling. If one piece moves, all the other pieces move as well. Every individual piece that is part of the mobile influences the other. However, every mobile is different. The large differences in balance between components of mobiles can be compared to the large variety of influences on fatigue in people. Patients first need to identify which factors seem especially important influencers of their own fatigue by sorting seven cards that are included in the booklet. They put the factor of which they think that it most influences their fatigue at the top and the factor that least influences their fatigue at the bottom. The seven cards are:

1) severe overweight,

2) disease activity,

3) day-night rhythm and sleep,

4) physical activity,

5) emotions and negative thoughts,

6) pain, and

7) another influence.

Interventions targeting these factors are discussed in separate sections of the booklet. Users are invited to start reading the sections with advice regarding the factors that most influence their fatigue. The foldable back cover of the booklet includes the set of seven cards of influencing factors, a diagram to make a 7-day 24-hours day-night rhythm schedule, and instructions to make an action plan.

Conclusion: In the Netherlands, the text can be obtained online and as a booklet in rheumatology departments of hospitals and through a national patient association, free of charge. The booklet was translated into English, which makes it accessible to a larger group of patients. It may take up to two months to successfully change lifestyle. It's an, as yet not empirically verified, hope that the booklet will be more successful than a traditional educational brochure.

References:

[1] Hewlett S, Almeida C, Ambler N, et al. Reducing arthritis fatigue impact: two-year randomised controlled trial of cognitive behavioural approaches by rheumatology teams (RAFT). Ann Rheum Dis 2019;78(4): 465-472.

[2] Overman CL, Kool MB, Da Silva JA, Geenen R. The prevalence of severe fatigue in rheumatic diseases: an international study. Clin Rheumatol 2016;35(2):409-415.

[3] Geenen R, Dures E. A biopsychosocial network model of fatigue in rheumatoid arthritis: a systematic review. Rheumatology (Oxford) 2019;58 (Supplement 5):v10-v21.

Disclosure of Interests: Rinie Geenen Speakers bureau: Sanofi Genzyme paid for a lecture on depression in RA.

DOI: 10.1136/annrheumdis-2020-eular.1123

\section{PARE0023 1 ORAL HEALTH IN RHEUMATOID ARTHRITIS: LISTENING TO PATIENTS}

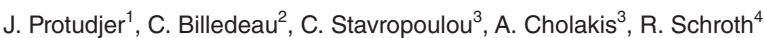
C. Hitchon ${ }^{5} .{ }^{1}$ University of Manitoba, Department of Pediatrics and Child Health, Winnipeg, Canada; ${ }^{2}$ Patient Representative, Winnipeg, Canada;

${ }^{3}$ University of Manitoba, Dental Diagnostics and Surgical Sciences, Winnipeg,

Canada; ${ }^{4}$ University of Manitoba, Department of Preventative Dental Science,
Winnipeg, Canada; ${ }^{5}$ University of Manitoba, Max Rady Department of Internal Medicine, Winnipeg, Canada

Background: Rates of periodontal disease and tooth loss are increased in rheumatoid arthritis (RA). Periodontal disease may exacerbate RA inflammation and complicate RA care. Understanding factors that contribute to the increased burden of periodontal disease in RA is critical to improving oral health and possibly arthritis outcomes. People with RA may have unique needs and/or barriers to maintain oral health.

Objectives: To determine from people with RA what are their experiences and perceptions about their oral health, their most important questions relating to oral health, and how they wish to receive oral health information.

Methods: Semi-structured interviews were conducted with RA patients. Recorded interview transcripts underwent iterative content analysis. Transcripts were initially reviewed to develop a coding guide. Latent content, or larger themes, were then applied to the transcripts. Constructs were considered saturated when no new themes were identified with subsequent interviews. We report identified themes with representative quotes.

Results: Interviews with 11 RA (10[91\%] female; all on RA medication) averaged 19 minutes (range 8-31 minutes) and were mostly conducted face-to-face. Many believed RA medication contributed to dry mouth. Most participants had not previously considered other links between oral health and RA. Themes identified included the need for complicated oral health routines, barriers of cost and access to dental care, and shame relating to oral health (Table 1). Participants preferred to receive oral health education from their rheumatologists or dentists over printed or online resources.

Conclusion: RA patients have unique needs relating to oral health and report poor oral quality of life. Strategies to optimize oral health in RA may include educational tools for optimizing oral self-care appropriate for RA, and improved access to oral care professionals who are aware of the needs of arthritis patients. Disclosure of Interests: Jennifer Protudjer: None declared, Corrie Billedeau: None declared, Chrysi Stavropoulou: None declared, Anastasia Cholakis: None declared, Robert Schroth: None declared, Carol Hitchon Grant/research support from: UCB Canada; Pfizer Canada DOI: 10.1136/annrheumdis-2020-eular.612

\section{PARE0024 AWARENESS ABOUT FAMILY PLANNING AND PREGNANCY EXPECTATION AMONG PATIENTS WITH CHRONIC INFLAMMATORY DISEASE OF THE SKIN OR JOINTS}

K. Schreiber ${ }^{1}$, C. Johansen ${ }^{2}$, U. F. Jensen ${ }^{3}$, A. Egeberg ${ }^{4}$, S. F. Thomsen ${ }^{2}$, A. L. Hansen ${ }^{3}$, T. B. Laurberg ${ }^{5}$, L. Skov ${ }^{4}$, L. E. Kristensen $6 .{ }^{1}$ Copenhagen Lupus and Vasculitis Clinic, Copenhagen University Hospital, Copenhagen, Denmark; ${ }^{2}$ Department of Dermatology and Venereology, Copenhagen University Hospital Bispebjerg, Copenhagen, Denmark; ${ }^{3}$ UCB Pharma, Copenhagen, Denmark; ${ }^{4}$ Department of Dermatology and Allergy, Herlev and Gentofte Hospital, University of Copenhagen, Copenhagen, Denmark; ${ }^{5}$ Department of Rheumatology, Aarhus University Hospital, Aarhus, Denmark; ${ }^{6}$ The Parker Institute, Frederiksberg Hospital, Copenhagen, Denmark

Background: Patients affected by chronic inflammatory diseases of the skin or joints (CIDs; including psoriasis [PSO], rheumatoid arthritis [RA], juvenile idiopathic arthritis [JIA], psoriatic arthritis [PsA], non-radiographic axial spondyloarthritis [nr-axSpA; reported in the survey as 'axSpA'], or ankylosing spondylitis [AS]) may be challenged in their attempts to have children. A multinational survey conducted in Europe and the US, including 969 patients, revealed that most

Table. Thematic analysis and quotes

\begin{tabular}{|c|c|c|}
\hline Theme & Description & Quote \\
\hline Oral-RA links & RA medications caused dry mouth & $\begin{array}{l}\text { The medications, really, really are awful on your mouth, in particular prednisone. I get very raw } \\
\text { gums... it [was] painful to brush my teeth. }\end{array}$ \\
\hline \multirow[t]{3}{*}{ Complicated oral care } & Time-demanding oral care routines. & $\begin{array}{l}\text { We don't have saliva to wash things away. We have a different mouth flora } \\
\text { The severe pain made it very hard to open my mouth to brush my teeth. The joint damage [makes }\end{array}$ \\
\hline & $\begin{array}{l}\text { Multiple oral health care tools and adaptations used depending on } \\
\text { current oral health, and RA activity. }\end{array}$ & $\begin{array}{c}\text { it] really hard to handle a toothbrush. } \\
\text { We have to have toothbrushes with a wide handle... and different attachments when we need } \\
\text { them. }\end{array}$ \\
\hline & & $\begin{array}{l}\text { Even with those [special] products, the pain sometimes was just overwhelming. I'm dedicated } \\
\text { about brushing my teeth, but boy, it was a struggle. It took me a long time to brush my teeth. }\end{array}$ \\
\hline \multirow[t]{2}{*}{$\begin{array}{l}\text { Access to professional } \\
\text { oral care }\end{array}$} & $\begin{array}{l}\text { Lack of dental insurance and costs of care } \\
\text { Logistical access: multiple dental visits. }\end{array}$ & $\begin{array}{l}\text { I have a hygienist, and a dentist, and a gum dentist and a bunch of dentists with fancy names. I } \\
\text { see them every } 3 \text { months. }\end{array}$ \\
\hline & $\begin{array}{l}\text { Physical access: attending appointments; prolonged sitting in a } \\
\text { dental chair. }\end{array}$ & $\begin{array}{l}\text { Dental offices have dental hygienists. And some of them are an A+, and some of them are C-... it's } \\
\text { important that hygienists are trained, that they really understand the tools. } \\
\text { When I go back in the [dental] chair, it was uncomfortable [when first diagnosed]. I struggled. I }\end{array}$ \\
\hline Shame due to oral health & $\begin{array}{l}\text { Shame relating to poor oral health. } \\
\text { Seeking oral care possibly considered unusual for their age. }\end{array}$ & $\begin{array}{l}\text { couldn't keep my mouth open. } \\
\text { I would feel ashamed. Something's wrong. Everyone around me has these beautiful teeth. I don't, } \\
\text { and something is wrong. }\end{array}$ \\
\hline & & I'm getting braces. At my age, I'm getting braces. \\
\hline
\end{tabular}

